УДК $338.4,658$

\title{
Д. А. Максимов
}

ФГБОУ ВО «Российский экономический университет им. Г. В. Плеханова», Москва, e-mail: maksimovdenis@mail.ru

\section{ПЕРСПЕКТИВЫ РАЗВИТИЯ ИТ-АУТСОРСИНГА В ИНТЕГРИРОВАННЫХ ПРОИЗВОДСТВЕННЫХ СТРУКТУРАХ}

Ключевые слова: холдинг, бизнес-единица, производственная и финансово-инвестиционная сферы рыночной деятельности предприятия, ИТ-аутсорсинг.

Для улучшения своих позиций и получения дополнительных преимуществ на конкурентном рынке современным производственным интегрированным структурам (холдингам и крупным корпорациям) необходимо применять инновационные информационные технологии в сферах производства, финансов и инвестиций. В статье рассматривается перспективное направления использования холдингами ИТ-аутсорсинга в условиях роста сложности и масштабности внедряемых ИТ-проектов, требуемых для их реализации аппаратно-вычислительных и программных средств и увеличения доли прямых и косвенных затрат на сопровождение и модернизацию ИТ-инфраструктуры. Инструментом повышения эффективности производственной и финансово-инвестиционной сфер рыночной деятельности управляющей компании и структурных подразделений холдинга, который призван решить проблему снижения затрат на ИТ и росту отдачи ИТ-технологий при планировании и управлении в этих сферах является аутсорсинг ИТ-услуг. При использовании этого способа управления ИТсистемами холдинга появляется возможность уменьшить затраты на ИТ в подразделениях холдинга и их долю этих в совокупных издержках интегрированной компании.

\section{A. Maksimov}

Plekhanov Russian University of Economics, Moscow, e-mail: maksimovdenis@mail.ru

\section{PERSPECTIVES OF IT OUTSOURCING DEVELOPMENT IN THE INTEGRATED PRODUCTION STRUCTURES}

Keywords: holding, business unit, production and financial and investment spheres of the company's market activity, IT outsourcing.

There is a need to apply innovation IT technologies in the field of production, finance and investments for the improvement its positions and additional advantages at the competitive market for modern production integrated structures (holdings and large corporations). The article covers perspective directions of IT outsourcing use by holdings in conditions of challenges in IT projects integration, required for its implementation of hardware, computing and software tools and increasing the share of direct and indirect costs for IT infrastructure maintenance and modernization. Outsourcing of IT services is an instrument to increase the production efficiency and investment spheres of the market activity for the managing company and structural divisions of the holding, which is intended to solve the problem of IT costs reduction and increase the IT-technologies return in planning and management in mentioned area of expertise. By using this method of managing the holding 's IT systems, it is possible to reduce IT costs in the holding 's divisions and their share in the total costs of the integrated company.

\section{Введение}

Современные интегрированные производственные структуры (холдинги), вне зависимости от их масштаба и сферы деятельности, существенно зависят от состава и уровня используемых информационных технологий, что отличает их внутрифирменную среду в сравнении даже с началом 2000$\mathrm{x}$ годов. Тенденция автоматизации и информатизации производственной и финансово-инвестиционной сфер как отдельной структурной бизнесединицы в составе холдинга, так и са- мого холдинга нарастает с каждым годом: появляются новые технологии, новые требования и перспективные направления повышения отдачи ИТинструментария. ИТ переходит в категорию основного актива холдинга, хотя раньше этот инструментарий оказывал только информационные услуги структурным бизнес-единицам. В настоящее время ИТ-процессинг включается в цепочку создания добавочной стоимости конечной продукции или услуг наравне с базовыми производственно-технологическими процессами $[2,3,5]$. 
Более того, затраты на ИТинструментарий и его сопровождение занимают значительную долю в общих затратах интегрированной компании. Замена устаревших серверов, приобретение необходимой вычислительной техники и компьютерного оборудования, внедрение более совершенных технологий и программных комплексов - все это позволяет компании быть конкурентоспособной и гибкой на рынке - быстро реагировать на его изменения, привлекать новых клиентов и предоставлять качественный сервис. С учетом того, что доля затрат на обслуживание и поддержку ИТ-систем постоянно растет, важно находить эффективные методы управления ИТ-инфраструктурой для уменьшения издержек на производство и улучшения качества производимой продукции и оказываемых услуг.

Цель исследования - обоснование методики количественной оценки экономической эффективности аутсорсинга ИТ-услуг в интегрированных производственных структурах. В рамках проводимого исследования предполагается определить типологию интегрированных производственных структур, для которых доступна оценка экономической эффективности ИТ-аутсорсинга, а также разработать классификационные группы с выделением объектов и диапазонов соответствующих им количественных характеристик.

\section{Материал и методы исследования}

В современной экономике преуспевающими предпринимательскими организациями являются холдинги, открытые к инновациям и современным трансформациям рыночной среды с целью повышения качества и эффективности управления $[14,15]$. Аутсорсинг ИТ-услуг - одна из многообещающих управленческих инноваций, которая активно внедряется в России, призванная решить многие проблемы интегрированных компаний, связанные с недостаточным качеством ИТ-услуг, дороговизной содержания штата ИТ-специалистов и т.д. $[6,8,10]$.

ИТ-услугой называется документально зафиксированный набор инструментов, поддерживаемых исполнителем и выполняющим функции, необходимые заказчику для ведения бизнеса. В различных сферах ИТ-услуги могут отличаться друг от друга составляющими, например: программное обеспечение, сервисная поддержка, оборудование, персонал и т.п. Пользователь воспринимает данные услуги как обособленный сервис, показатели качества и критерии использования которого установлены и прописаны в SLA (Service Level Agreement - соглашение об уровне обслуживания). Использование этого стандарта к ИТ-услугам помогает управлять ИТ-службой холдинга в рамках стандартизации процессов предоставления совокупности услуг по поддержке ИТ-сервисов $[7,9]$.

ИТ-сервисом называется набор ИТсистем, используемых управляющей компанией и подразделениями холдинга для принятия решений в производственной и финансово-инвестиционной сферах деятельности. В узком смысле ИТ-сервисом являются услуги, оказываемые конечному пользователю - работнику предприятия, являющиеся неотьемлемой частью его рабочего процесса. Наиболее востребованными ИТ-услугами являются:

- ремонты оборудования и оргтехники;

- обслуживание автоматизированных рабочих мест, серверных платформ, локальных вычислительных сетей, корпоративных сетей передачи данных, мультисервисных телекоммуникационных решений;

- поддержка ИТ-проектов заказчика;

- поддержка системы управления ПО, пользовательского ПО, прикладного ПО, ОС, СУБД и прикладного серверного ПО; - поддержка процессов управления ИТ-активами.

Прямое влияние на достижение стратегических целей холдинга на рынке оказывают внедренная и поддерживаемая ИТ-инфраструктура и качество ИТ-услуг. [13].

\section{Результаты исследования и их обсуждение}

ИТ-аутсорсинг давно присутствует на мировом рынке. В России ИТаутсорсинг стал активно использоваться в последние 10 лет: появились ИТ-интеграторы, ИТ-аутсорсеры, способные предоставить должное качество услуг, защитить информацию заказчика, предоставить проектный опыт [10]. 
Актуальные данные по российскому рынку ИТ-услуг приведены аналитическим агентством TAdviser (рис. 1). Только по результатам 2016 г. он вырос на $4 \%$ в сравнении с предыдущим годом, достигнув размера 306,4 млрд руб.

По результатам опросов ключевых игроков этого сектора, 2017 и 2018 гг. период быстрого роста и изменений. Основными российскими интеграторами и лидерами рынка ИТ-услуг были и остаются: Техносерв, Ланит, КРОК, АйТеко, Инфосистемы Джет.
Кроме того, стоит рассмотреть динамику рынка именно аутсорсинговых услуг, т.к. важно понимать, пользуется ли спросом этот сервис и имеет ли он перспективы развития в будущем. Аналитические агентства сообщают, что по сравнению с прочими услугами ИТаутсорсинг имеет положительную тенденцию роста от года к году. Уже в 2016 г. он вырос на $16 \%$ в сравнении с предыдущим годом, а в 2017 и 2018 гг. сохранил положительную динамику на уровне $15 \%$ (рис. 2).

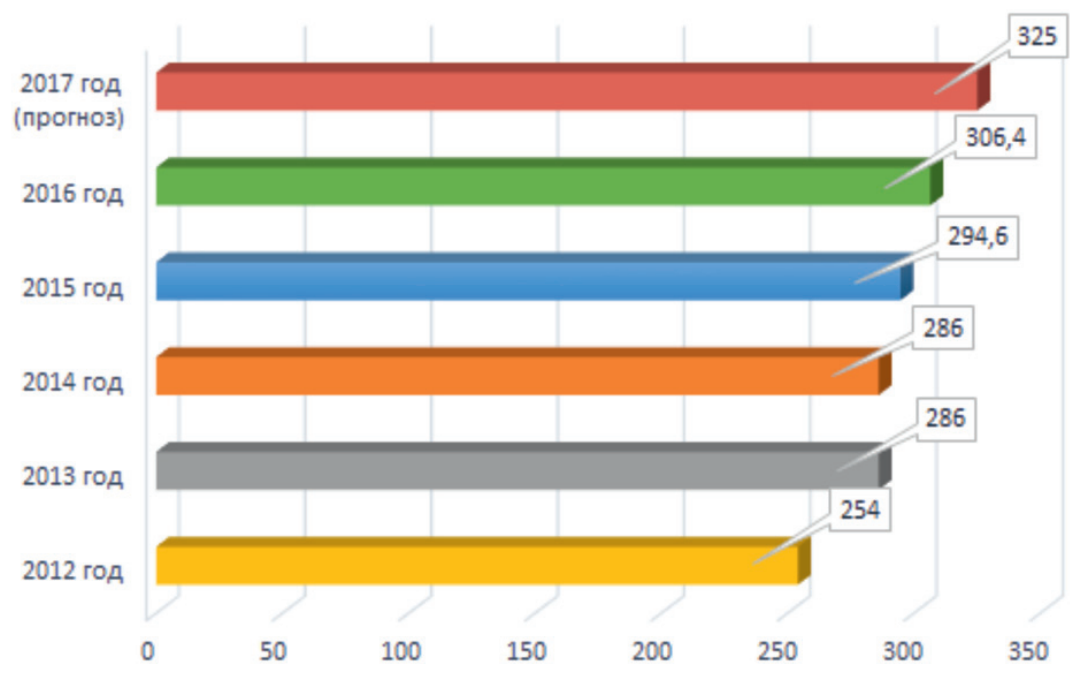

Рис. 1. Динамика российского рынка ИТ-услуг (млрд. руб.)

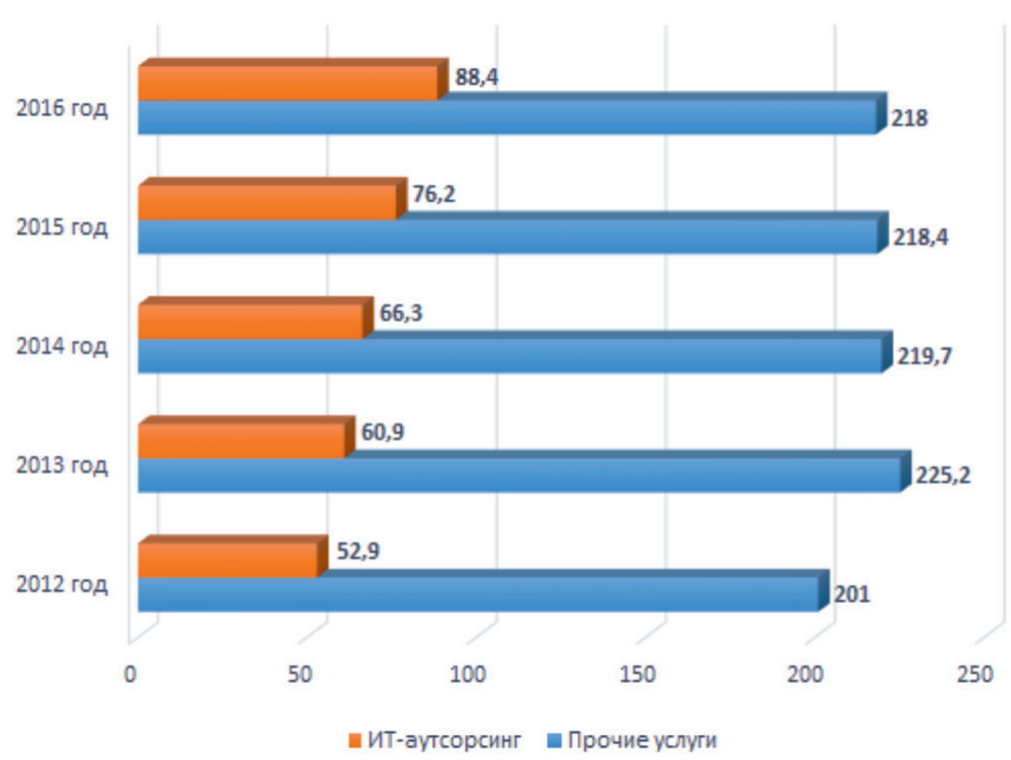

Рис. 2. Анализ рынка ИТ-услуг (млрд. руб.) 
Данный рост ИТ-аутсорсинга в России обусловлен экономической ситуацией, в которой компаниям приходится находить новые способы управления бизнесом и развитием информационных технологий.

Если говорить об ИТ-отрасли в целом, то это наиболее активно развивающееся направление рынка инфокоммуникационных технологий и экономики в целом. Самый большой объем продукции/услуг в ИТ сфере производят компании, занимающиеся услугами по разработке ПО, услугами по обработке данных и размещению информации, консультативными услугами в сфере ИТ.

ИТ-аутсорсинг - передача компанией-заказчиком функций по управлению ИТ-инфраструктурой или отдельными ее частями компании-аутсорсеру на внешнее обслуживание. Компания-аутсорсер обязуется выполнить принятые функции в соответствии с подписанным Соглашением об уровне сервиса по зафиксированной цене и в установленные сроки [12].

Функция аутсорсинга ИТ-услуг - peструктуризация затрат в связи с переходом части постоянных затрат в переменные. Подобная мера выгодна в случае низкой загрузки работников сферы ИТ и изменчивости в загрузке ИТ-системы, связанных с влиянием рыночных факторов. Заметим, что сотрудники аутсорсинговой компании обладают знаниями и профессиональными навыками, что позволяет лучше штатных сотрудников справиться с возложенными функциями. ИТ-аутсорсинг в большинстве случаев рассматривается как возможность минимизации затрат, а также надежный способ сфокусировать усилия на основной деятельности компании, избавляясь от непрофильных активов [4].

Функции, передаваемые на управление внешним исполнителям, могут быть и ключевыми, и вспомогательными. Ориентируясь на п. 4.1 международного стандарта MC ISO ${ }^{1}$ 9001:2000, заметим, что любое решение о привлечении внешних компаний должно быть принято с учетом организации управления процессами, влияющими на соответствие продукции требованиям стандарта [13]. Другими словами, задача предприятия, обращающегося за помощью к аутсор- синговым компаниями, - создать условия для контроля соответствия товара/ услуг требованиям конечного потребителя. Уровень управления процессом аутсорсинга определяется важностью процесса, степенью производственного риска и компетентностью поставщика услуг (внешней организации, оказывающей услугу ИТ).

Таким образом, базовое требование к любому холдингу, желающему использовать услуги сторонней компании в своей деятельности, - определение уровня и качества управления этим процессом.

Представим, что ИТ-инфраструктура холдинга являет собой группу ИТсервисов, каждый из которых выступает в роли бизнес-единицы. Командные процессы ИТ-подразделений являются важной частью бизнес-единиц всего холдинга.

Применение процессного подхода позволяет экономистам провести расчет затрат, связанных с эксплуатацией подразделений ИТ, а также сопоставить совокупные затраты на единицу сервиса со стоимостью обслуживания данного сервиса ИТ-аутсорсером. Если окажется, что стоимость услуг по аутсорсингу ниже расходов на организацию собственного штата работников, целесообразно обращаться за помощью к сторонней компании. Условие перехода к услугам ИТ-аутсорсинга представлено следующим образом:

$$
\mathrm{D}=\mathrm{X}^{*}(\mathrm{R}+\mathrm{Q}) / \mathrm{T}-\mathrm{A}>0,
$$

где $\mathrm{X}$ - предполагаемые трудозатраты на ИТ-сервис в часах;

$\mathrm{R}$ - размер заработной платы сотрудника в месяц;

Q - величина косвенных затрат на сотрудника;

T - количество отработанных часов в месяц;

А - стоимость услуг аутсорсера, поддерживающего ИТ-сервис.

В случае, если $\mathrm{D}>0$, компании целесообразно прибегнуть к помощи аутсорсера.

Заметим, что затраты на формирование и развитие ИТ определяются как инвестиции. Следовательно, они должны быть экономически оправданными. Любое ИТ-подразделение оказывает услуги конечным потребителям для реали- 
зации бизнес-процессов. Как известно, каждый бизнес-процесс не может существовать без информации, предоставляемой ИТ-сервисами. В свою очередь, менеджеры рассматривают ИТ-сервисы как инвестиционный проект. Если отказаться от этого проекта на этапе реализации, капиталовложения полностью или частично вернуть не удастся.

При оценке инвестиций используют классический способ определения чистой приведенной стоимости проекта (NPV) с учетом следующих предположений: 1) капиталовложения обратимы, то есть они могут быть возвращены, хотя рыночная конъюнктура вполне может оказаться неблагоприятной; 2) инвестиции необратимы - если холдинг не принимает их сейчас, то отказывается от проекта навсегда.

Рассмотрим классификацию по численности сотрудников. Универсальных критериев, разграничивающих холдинги на малые, средние и крупные, не существует. В каждой стране установлены свои параметры группировки, которые зависят от отрасли экономики, нюансов производства и некоторых национальных особенностей. В России усредненный за предыдущий календарный год показатель численности работников не может превышать лимит сотрудников для каждой категории субъектов хозяйствования:

a) $101-250$ сотрудников - для средних предприятий;

б) до 100 сотрудников - для представителей малого бизнеса, для микропредприятий - до 15 сотрудников [1].

В качестве классификационного критерия распределения холдингов выступает также число автоматизированных рабочих мест (сокращенно АРМ). APM - аппаратно-программный комплекс на базе технического оборудования, предназначенный для ускорения и автоматизации персональной деятельности сотрудника предприятия. Например, это может быть компьютер с ПО или средства телефонной связи. В отдельных случаях рабочее место укомплектовано периферийным оборудованием. На основе показателя «количество АРМ» проводится расчет масштаба и эффективности ИТ-системы. Как ранее отмечалось, ИТинфраструктура - совокупность специа- лизированного ПО, техники, интеграционной платформы, систем для хранения и резервирования информации, каналов коммуникации, технических и информационных средств защиты. К инфраструктурным объектам ИТ принадлежит конфигурационная единица (KЕ), контролируемая процессом управления. К КЕ относят аппаратные средства, все виды ПО, пассивные и активные элементы сети, системные блоки, серверы, процедуры, документы и прочие компоненты, попадающие в зону контроля ИТведомства, отвечающего за управление конфигурациями (ITIL/ITSM). Обратим внимание, что КЕ является объектом финансового/бухгалтерского учета на ее основе определяются амортизационные отчисления, уценка, проводится расчет стоимости услуг, предоставляемых комплексом, в состав которого входит объект.

Одним из главных ресурсов любого предприятия выступает ИТ-персонал. Сотрудники ИТ службы занимают следующие должностные позиции: программисты и администраторы баз данных, инженеры компьютерного оборудования, системные администраторы, специалисты по информационной безопасности, специалисты технической поддержки.

При внедрении АРМ ключевые операции аккумуляции и трансформации данных возложены на вычислительную технику. В компетенции пользователя находится выполнение тех операций, которые основаны на творческом подходе и принятии управленческих решений.

Число АРМ на предприятии вычисляется на основе данных, представленных в [1].

На базе этой информации можно сделать вывод, что уровень компьютеризации в компаниях достигает 35-55 \% от числа персонала. Распределение АРМ для рассмотренных в работе компаний A, B, С осуществляется следующим образом (табл. 1).

Получены числовые значения, демонстрирующие соотношение числа персонала к количеству АРМ. Эти показатели будут применяться при определении затрат по организации ИТ-сервисов на исследуемых предприятиях. 
Количество АРМ с учетом категорий предприятий

\begin{tabular}{|l|c|c|c|}
\hline \multicolumn{1}{|c|}{ Категория предприятия } & А & В & С \\
\hline Количество сотрудников, чел. & до 100 & $101-250$ & свыше 250 \\
\hline Количество АРМ, шт. & до 55 & $55-135$ & свыше 135 \\
\hline
\end{tabular}

Таблица 2

Классификация компаний по ИТ-параметрам

\begin{tabular}{|l|c|c|c|}
\hline \multicolumn{1}{|c|}{ Параметр / Категория предприятия } & А & В & C \\
\hline Численность персонала, чел. & 100 & 250 & 700 \\
\hline Количество АРМ, шт. & 42 & 142 & 350 \\
\hline Численность ИТ-подразделения, чел. & 2 & 5 & 8 \\
\hline
\end{tabular}

Каждый холдинг представляет собой систему, в которой происходит функциональное разделение трудовых операций между структурными элементами, связанными общими целями и используемыми ресурсами. Для изготовления товаров и услуг применяются предметы и средства труда, которые после воплощения в готовых объектах обязаны нести большую ценность, чем входящие ресурсы. К потребляемым ресурсам принадлежат персонал, производственные мощности, денежные потоки и прочие активы, которыми как раз и являются локально-вычислительные сети (ЛВС).

Руководствуясь этими соображениями, проведем исследование организационных структур с ориентацией на ИТинфраструктуру. Чтобы решить эту задачу, для каждой организационной структуры определяют количественные показатели: количество АРМ и численность персонала ИТ подразделения.

Установлены типовые нормы времени, используемые для расчета численности штата ИТ-работников. В связи с развитием информационных технологий система информатизации претерпевает глобальные изменения, в частности, действующие ранее нормы устаревают. Точно определить численность ИТсотрудников крайне тяжело. Руководствуясь рекомендациями, полученными на базе статистических мировых исследований ITIL (IT Infrastructure Library), проведем расчет. Приняв рекомендации за рациональные, распределение функ- ций сотрудников ИТ-служб для предприятий категории А выглядит следующим образом:

- системный администратор - 1 чел/ до 80 АРМ;

- сервисный инженер - 1 чел/ до 80 АРМ.

При определении числа работников будем основываться на том, что в связи с невыходом конкретного специалиста на работу по различным причинам (больничный, отпуск и т.д.) в службе должен числиться работник нужного уровня квалификации, который справится с текущими задачами (так называемый кадровый резерв). Следовательно, для предприятия категории А с общим числом сотрудников до 100 человек будет сформировано до 55 АРМ с численностью ИТ-персонала в 2 единицы.

Аналогично проведены исследования для предприятий типа В и С. Результаты анализов для всех категорий представлены в табл. 2.

\section{Выводы}

Проведенные исследования позволили установить количественный состав элементов ИТ-инфраструктуры холдингов любого масштаба, что необходимо для определения затрат на единицу ИТ-сервиса. Перевод компании на аутсорсинг ИТ-услуг является экономически эффективным способом управления ИТ-инфраструктурой. Однако, для принятия корректного управленческого решения по вопросу, следует ли управляющей компании холдинга передавать 
ИТ-функции на внешнее обслуживание, важно провести детальный анализ стратегических целей, определить объем передаваемых услуг, оценить важность передаваемой на внешнее управление информации и другие факторы внешней и внутренней сред деятельности. Аутсорсинг - лишь один из инструментов организации рыночной деятельности хозяйствующего в условиях рыночной экономики субъекта, и его использование должно быть аргументировано.

\section{Библиографический список}

1. Алгазинов Э.К., Сирота А.А. Анализ и компьютерное моделирование информационных процессов и систем. М.: Диалог-МИФИ, 2009. 416 с.

2. Бельченко С.В., Халиков М.А., Щепилов М.В. Управление трансакционными издержками интегрированной группы предприятий: модели и методы. М., 2011. 171 с.

3. Гельфанд А.О. История возникновения и развития рынка ИТ-аутсорсинга // Заметки ученого. 2015. № 3. C. 26-28.

4. Генкин Б.М., Свистунов В. М. Основы организации труда. М.: Норма, 2008. 400 с.

5. Емельянов П.С., Халиков М.А. Сравнительный анализ современных методов учета затрат на производство промышленной продукции // Современные аспекты экономики. 2005. № 11 (78). C. $165-178$.

6. Клементе С., Доннеллан М., Рид С. Аутсорсинг бизнес-процессов. Советы финансового директора. М.: Вершина, 2006. $416 \mathrm{c}$.

7. Копеева А.С. Проблемы процесса перехода ИТ-подразделений (it teams) на аутсорсинг и варианты решения // ИТ портал. 2016. № 2 (10). С. 4.

8. Кремин А.Е. Проблемы использования ИТ-аутсорсинга для экономики России // Научный вестник Южного института менеджмента. 2019. № 3 (27). С. 5-13.

9. Лашина М.В., Соловьев Т.Г. Информационные системы и технологии в экономике и маркетинге. М., 2017, 302 с.

10. Николаева Я.И., Пальмов С.В. Преимущества обслуживание на условиях ИТ-аутсорсинга // Форум молодых ученых. 2019. № 2 (30). С. 1108-1111.

11. Новиков Е.М., Петрище Ф.А. Эффективность услуг ИТ-аутсорсинга на предприятии // Фундаментальные и прикладные исследования кооперативного сектора экономики. 2012. № 1. С. 19-24.

12. Олейник А.И., Сизов А.В. ИТ-инфраструктура. М.: ИД ВШЭ, 2012. 135 с.

13. Типовые организационные структуры предприятий [Электронный ресурс] // http://www.cfin. ru/management/iso9000/iso9000_orgchart.shtml (дата обращения: 12.01.2020).

14. Халиков М.А. Дискретная оптимизация планов повышения надежности функционирования экономических систем // Финансовая математика: Сборник статей. М., 2001. С. 281-295.

15. Хачко О.И., Машковцева Н.А. Сравнительный анализ электронных платежных систем // Путеводитель предпринимателя. 2019. № 44. С. 211-222. 